\title{
On The Effect Of The Shape Of Buildings And Chimneystacks On Ventilation And Pollutant Dispersion
}

\author{
Simone Ferrari ${ }^{1, *}$, Maria Grazia Badas $^{1}$, Michela Garau ${ }^{1}$, Luca Salvadori $^{1}$, Alessandro Seoni ${ }^{1}$ and , Giorgio Querzoli ${ }^{1}$ \\ ${ }^{1}$ DICAAR - Dip. Ingegneria Civile, Ambientale e Architettura, University of Cagliari, via Marengo 2, 09123 Cagliari, Italy
}

\begin{abstract}
The purpose of this work is to investigate the modifications induced by the change of the roof shape in the flow field, inside and above the buildings, with an attention to their capability to modify the air quality and the dispersion of pollutants released from chimneystacks. We have carried out laboratory experiments on arrays of identical buildings, with symmetrical dual-pitched or flat roofs, and chimneystacks of different heights and positions. The experiments have been carried out in a close-loop water-channel, where two non-intrusive and quasi-continuous in space Digital Image Analysis technique have been implied to measure the velocity fields (Feature Tracking Velocimetry) and the concentration fields (Laser Induced Visualization). Results have highlight the meaningful role of gabled roofs in modifying turbulence, which increases the air exchange rate between the street canyon and the outer flow, but, in some conditions, they increase the dragging of pollutant inside the canyon. These results can have an immediate practical impact on the building design and on planning strategies, as the roof shape can be a useful tool to enhance natural ventilation and pollutant, humidity and/or heat dispersion, i.e. the air quality in urban and industrial areas.
\end{abstract}

\section{Introduction}

The effect of wind on civil and industrial structures and on human comfort and health is a fundamental issue for engineers and urban planners. As reported on Tamura and Yoshie (2016) [1], almost $70 \div 80 \%$ of world economic losses due to natural disasters are caused by extreme winds and related water hazards. Most of the world's population, nowadays, resides in large urban built-up areas, that are sources of heat and pollutants (with the main causes being the vehicular traffic and the heating systems). The accumulation of pollutants and heat can often reaches values that can be damaging to the environment and the inhabitants. Consequently, this huge urbanization can lead to a potential deterioration of environmental quality and public health.

The dispersion of a pollutant in a urban or industrial built environment depends on the type, quantity and position of the release in the atmosphere, as well as on the field of motion in which it develops which, in turns, depends on the characteristics of the urban or industrial canopy. Understanding the dynamics of flows and the mechanisms of pollutant dispersion or accumulation in a built environment is therefore of fundamental importance. In particular, it is known that the geometry of the buildings has a significant influence on ventilation, or on the capacity of air exchange between the canyon and the free atmosphere (see e.g. Xie et al., 2005 [2]; Rafaidilis, 1997 [3]; Yassin, 2011 [4]; Takano and Moonen, 2013 [5], Ferrari et al., 2016 [6],Badas et al., 2017 [7], Ferrari et al., 2017 [8], Garau et al., 2018 [9]) and, consequently, on air quality.
Moreover, roof shapes different from the flat one, such as the pitched roofs, are a widespread typology in many regions all around the world.

The effect of the inclination of the roofs of the buildings and of the position of the chimneystack on them is one of the aspects not yet sufficiently investigated. Meroney et al. (1996) [10] studied the dispersion of a pollutant released from a line source, placed at the street level, between two flat roof buildings, simulating vehicular emissions. Craig et al. (1999) [11] numerically simulated via CFD (Computational Fluid Dynamics) the optimal location of pollutant sources in flat roof industrial canyons. Bagieński (2006) [12] investigated in the laboratory the dispersion of a pollutant, released form a source with various positions, in a single street canyon with flat roof. Mensink and Cosemans (2008) [13] performed a traffic flow simulations, in order to measure the pollutant concentrations in street canyons and backyards, via an integrated modelling approach, where they coupled a street canyon model and a Gaussian model. BaratianGhorghi and Kaye (2013a [14] and 2013b [15]) investigated in the laboratory the mechanics of sheardriven flushing of a dense fluid, released from a linear source on the floor, from an isolated flat roof building canyon, for various canyon aspect ratios. Souto et al. (2014) [16] applied the CALMET/CALPUFF modelling system to simulate the local dispersion of a pollutant from the chimneystack of a coal-fired power plant, considering both different chimneystack configurations and meteorological inputs. Ghermandi et al. (2015a [17] and 2015b [18]) presented a simulation of the dispersion

*orresponding author: ferraris@unica.it 
of a pollutant released from the chimneystack of a power plant. Nosek et al. (2016 [19] and 2017 [20]) performed wind-tunnel experiments to analyse the ventilation processes and the removal mechanism of traffic pollutions in different street canyons, with variable roof geometry, using a ground-level line source. Di Bernardino et al. (2017 [21] and 2018 [22]) measured both velocity and concentration fields in a water channel in order to evaluate the dispersion of a pollutant emitted at street level from a line source within a twodimensional flat-roof urban canyon. A point source was instead studied by Di Bernardino et al. (2017) [23]: they investigated in the laboratory the turbulence and dispersion around an isolated cubic obstacle, where the pollutant emission was simulated by means of three point sources close to the cube.

As a consequence, the purpose of this work is to improve the knowledge on the influence of both roof shape and chimneystack position on the flow field, inside and above the buildings, with a particular attention to their capability to improve the air quality and the dispersion of pollutants released from chimneystacks of different position and height.

This work is a part of a larger project, carried on by the Hydraulic group of the University of Cagliari (Italy), with the main target to improve the forecasting of the air quality and of the pollutant dispersion or accumulation, according to the wind direction, in the different area of Cagliari metropolitan area, in order to help urban and traffic planners.

\section{Experimental set-up and data elaboration}

The laboratory investigations are here focused on the microscale, where a good air quality is fundamental both outdoor (at pedestrian level) and indoor (ventilation through windows).

As a consequence, the laboratory experiments have been carried out, in the Hydraulics Laboratory of the University of Cagliari (Italy), on arrays of identical buildings (idealized two dimensional street canyon, see Figure 1), with symmetrical dual-pitched roofs with a slope of $0^{\circ}$ (flat roof, Figure 2) and $45^{\circ}$ (Figure 3), and chimneystacks of different heights $h$ and position with respect to the roof, releasing a passive tracer, simulating the pollutant.

The aspect ratio $\mathrm{AR}$ was constantly equal to 1 ( $A R=H / W$ where $H$ is the height at eave level and $W$ is the canyon width, see Figure 4), i.e. in the skimming flow regime according to the Oke classification (1998) [24]. The value of $A R=1$ was chosen also in according with the data obtained in Badas et al., 2018 [25], where a morphometric site-specific analysis was performed on the city of Cagliari. H was kept constant for both flat roof and pitched roof buildings, i.e. the eave height was kept constant, in order to also keep constant the habitable volume, the most significant parameter in urban planning.

The experiments have been carried out in a closeloop water-channel with glass walls, where two non- intrusive and quasi-continuous in space Digital Image Analysis technique have been implied to measure the velocity fields (via Feature Tracking Velocimetry - FTV) and the concentration fields (via Laser Induced Visualization - LIV). The water channel has a section of $400 \times 500 \mathrm{~mm}^{2}$ and a length of $8 \mathrm{~m}$.

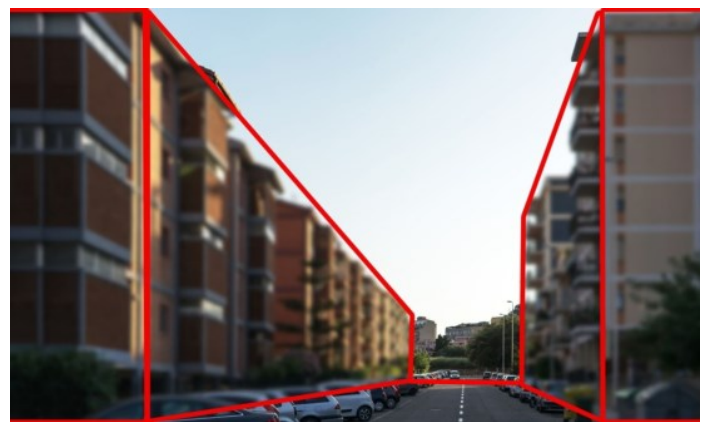

Fig. 1. Example of a real flat roof bidimensional urban canyon in the city of Cagliari (Italy).

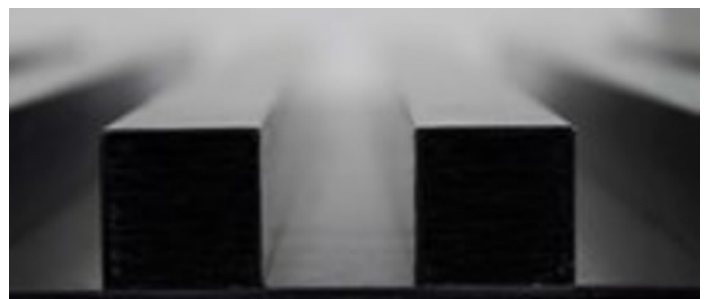

Fig. 2. Laboratory model of a flat roof bidimensional urban canyon.

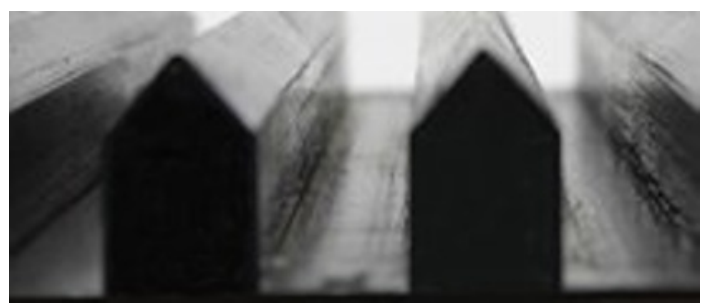

Fig. 3. Laboratory model of a pitched roof bidimensional urban canyon.

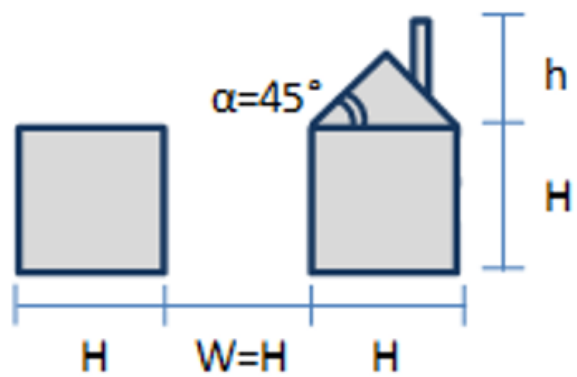

Fig. 4. Parameters to define the geometry of canyon and buildings.

With the aim of obtaining the logarithmic velocity profile, typical of the atmospheric boundary layer, and a fully developed turbulence, a square mesh grid, $80 \mathrm{~mm}$ thick, with a section equal to that of the channel has been positioned at the beginning of the channel and a series of panels, with stones of an equivalent diameter of $0.5 \mathrm{~cm}$, were placed, on the bottom if the channel, for a total length of $3 \mathrm{~m}$. The velocity profile obtained in this way 
has been validated, in terms of average and turbulent quantity, following Farell and Iyenga, 1999 [26].

The urban canyons have been modelled as an alignment of 20 identical two-dimensional buildings, with a $20 \times 20 \mathrm{~mm}^{2}$ section and a flat or double-pitched (with an inclination of $45^{\circ}$ ) roof. The section of the buildings was chosen so as to approach the optimal value of the obstruction factor (ratio between the height of the obstacle and the total height of the channel) which, as suggested by Blocken (2015) [27], should not exceed $3 \%$. The measurements were performed in the $17^{\text {th }}$ downstream canyon, in order to obtain a fully developed flow.

The flow rate in the water channel was adjusted in order to obtain a Reynolds number, $\mathrm{Re}=\mathrm{U}_{\mathrm{H}} \mathrm{H} / \mathrm{v}$ (calculated at the height of the building, with $v$ being the water viscosity) which respects the condition suggested by Hoydysh (1974) [28], i.e. $\operatorname{Re}>3400$, to guarantee to simulate the turbulent flow condition found in the atmosphere. The value obtained in our experiments is $\mathrm{Re}=4600$.

As a tracer, in order to simulate the release of pollutants from a point source into the atmosphere, a solution of water and $\mathrm{TiO}_{2}$ (titanium dioxide) was employed: the solution was contained in a constant-head closed hydraulic circuit and released in the flow with concentration $\mathrm{C}_{0}$ through a chimneystack of height $\mathrm{h}$ (Fig. 5), with negligible velocity compared to that of the incident flow.

Nine different configurations have been studied, by varying three positions of the chimneystack on the building (on the upstream and downstream pitch for the pitched roof and on the middle of the roof for flat roof) and three heights: $\mathrm{h} / \mathrm{H}=0.25$ (i.e. a chimneystack lower than the pitched roof peak), $\mathrm{h} / \mathrm{H}=0.5$, (i.e. a chimneystack with the same height as the pitched roof peak) and $\mathrm{h} / \mathrm{H}=0.75$ (i.e. a chimney stack taller than the pitched roof peak).

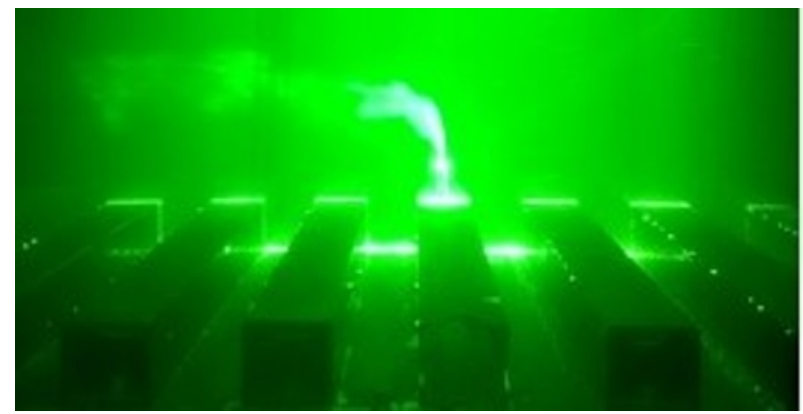

Fig. 5. An example of tracer emission from the chimneystack.

In order to perform quantitative measurements via Digital Image Analysis (DIA) techniques (see Ferrari, 2017 [29], for a review), the instrumental set-up for measurements of velocity and concentration fields (Figure 6) consists of a solid-state laser with continuous green light (532 nm), a cylindrical lens to warp the laser beam into a sheet, a mirror for laser sheet reflection and a high-speed high-resolution camera. Experiments were recorded with a resolution of $2240 \times 1760$ px at a frequency of $200 \mathrm{~Hz}$.
In the case of velocity field measurements, the FTV (Feature Tracking Velocimetry) technique was used, which proved to be more suitable than the traditional PIV for flows with high speed gradients (Besalduch et al., 2013 [30] and 2014 [31]). To perform this technique, the fluid was seeded with non-buoyant particles (pine pollen of $20 \mu \mathrm{m}$ mean diameter), uniformly dispersed into the water before the experiments.

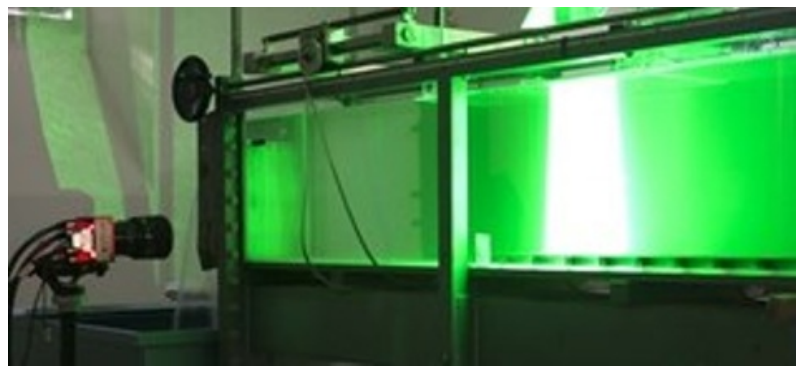

Fig. 6. Experimental configuration.

For the concentration field measurements, we relied on LIV (Light Induced Visualization), a technique similar to LIF (Light Induced Fluorescence), in which the tracer absorbs light at a given wavelength and reemits it on the whole spectrum, instead of on a single wavelength as in LIF. With the employed concentrations of $\mathrm{TiO}_{2}$, the concentration field is proportional to the light intensity, so a quantitative measure of the concentration is allowed. Both the FTV and LIV codes were designed, developed and optimized in-house by the Hydraulics Group of the University of Cagliari, which holds a strong expertise in the design, development and optimization of DIA techniques to measure concentrations (Ferrari and Querzoli, 2010 [32], Ferrari et al., 2015 [33], Ferrari et al., 2018a [34] and 2018b [35]), wave position (Ferrari et al., 2016 [36]), velocity (Querzoli, 1996 [37], Badas and Querzoli, 2011 [38], Simone et al., 2013 [39], Garau et al., 2018 [40]) and accelerations (Ferrari et al, 2007 [41], Ferrari and Rossi, 2008 [42], Ferrari et al, 2008 [43], Lardeau et al., 2008 [44], Rossi et al, 2009 [45]), in the civil and industrial (such as in the present paper or in Garau et al., 2017 [46]), environmental and biomedical fields (Badas et al., 2015 [47], Espa et al, 2012 [48]).

\section{Results}

This section is divided into two subsections: in the first one, the mean velocity fields for both flat roof and pitched roof will be shown, in order to show the modifications induced on the wind flow by the different roof shapes; in the second subsection, the mean concentration fields will be shown. In all the Figures from 7 to 17 , the flow moves from the right to the left, the $\mathrm{X}$ - and $\mathrm{Y}$-axis are non-dimensionalized by the building height $\mathrm{H}$, the origin of the $\mathrm{X}$-axis is placed on the middle of the first canyon downstream of the chimneystack and the origin of the $\mathrm{Y}$-axis is at the street level (bottom of the water channel). 


\subsection{Velocity fields}

The fields of the intensity of the non-dimensional mean velocity $\mathrm{U} / \mathrm{U}_{0}$, where $\mathrm{U}_{0}$ is the free-stream velocity measured at $\mathrm{Z} / \mathrm{H}=7$, are shown in false colours in Figure 7, for the flat roof case, and in Figure 8, for the pitched roof case. High velocity values are reported in dark red, low ones in dark blue; moreover, the streamlines are overlapped in white.

In both the flat and pitched roof case, a single vortex develops in the space inside the canyon, with two smaller counter-rotating vortices close to the upstream and downstream angles between the building vertical wall and the bottom of the canyon, in according to the skimming flow condition predicted by Oke (1988) [24]. Despite these similarities, the presence of the pitched roof increases the dimension of the three vortices, stretching them toward the vertical direction and moving towards higher $\mathrm{Z} / \mathrm{H}$ values their centres.

In addition, the influence zone, i.e. the zone above the canyon where its effect in reducing the velocity is visible, is larger for the pitched roof case than for the flat roof one, highlighting the greater capability of the pitched roofs to modify the outer flow. This has an implication also on the streamlines, because they are almost unperturbed above the flat roof canyon, whilst a hyperbolic stagnation point generates above the downstream pitch of the pitched roof canyon. This stagnation point separates a group of streamlines entering into the canyon from the ones that moves above it, in fact separating the flow coming into the canyon (the dragging zone) from the one that only moves above it.

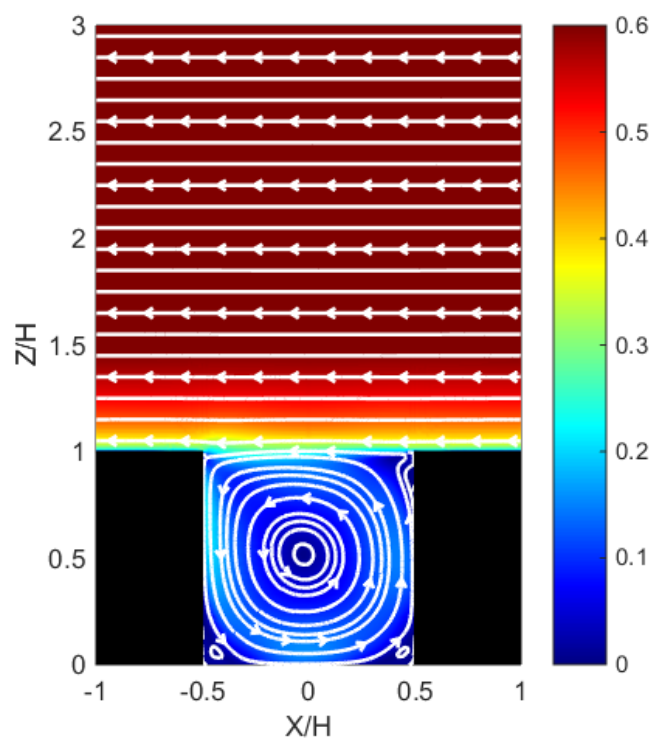

Fig. 7. Mean field of the non-dimensional intensity of the velocity, $\mathrm{U} / \mathrm{U}_{0}$, for flat roof $\left(\mathrm{U}_{0}\right.$ is the free-stream velocity); the flow moves from the right to the left; the white lines are streamlines.

More details on the modifications imposed by a pitched roof canyon in the flow, on the turbulence characteristics and on the air exchange between the inner and the outer flow can be found in Badas et al. (2017) [7] and in Ferrari et al. (2017) [8].

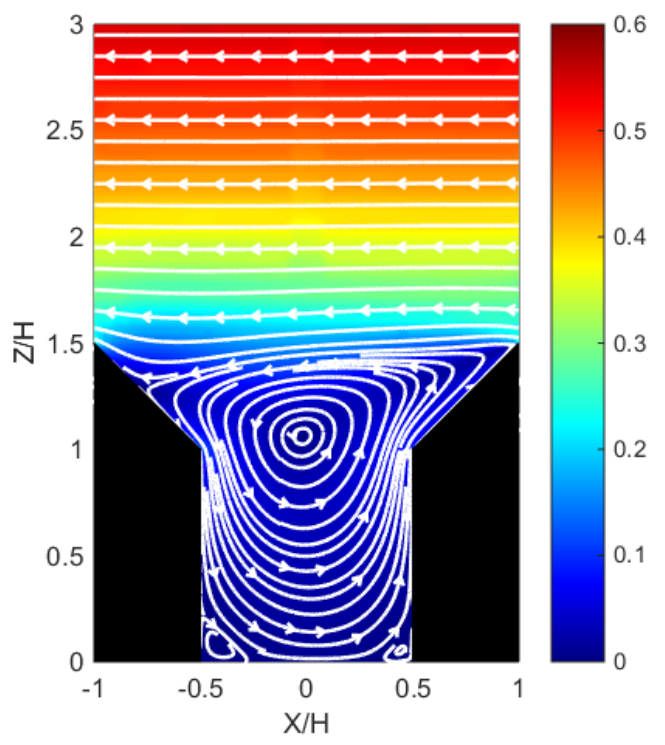

Fig. 8. Mean field of the non-dimensional intensity of the velocity, $\mathrm{U} / \mathrm{U}_{0}$, for pitched roof ( $\mathrm{U}_{0}$ is the free-stream velocity); the flow moves from the right to the left; the white lines are streamlines.

\subsection{Concentration fields}

The fields of the mean non-dimensional concentration $\mathrm{C} / \mathrm{C}_{0}$, where $\mathrm{C}_{0}$ is the mean concentration measured at the top of the chimneystack (i.e. the concentration of the released tracer), are shown in false colours from Figure 9 to Figure 17: high concentration values are reported in dark red, low ones in dark blue.

The flat roof cases with the chimneystack on the middle of the roof are reported on Figure $9(\mathrm{~h} / \mathrm{H}=0.25)$, Figure $10(\mathrm{~h} / \mathrm{H}=0.50)$ and Figure $11(\mathrm{~h} / \mathrm{H}=0.75)$.

The pitched roof cases with the chimneystack on the upstream pitch of the roof are reported on Figure 12 $(\mathrm{h} / \mathrm{H}=0.25)$, Figure $13(\mathrm{~h} / \mathrm{H}=0.50)$ and Figure 14 $(\mathrm{h} / \mathrm{H}=0.75)$.

The pitched roof cases with the chimneystack on the downstream pitch of the roof are reported on Figure $15(\mathrm{~h} / \mathrm{H}=0.25)$, Figure $16(\mathrm{~h} / \mathrm{H}=0.50)$ and Figure 17 $(\mathrm{h} / \mathrm{H}=0.75)$.

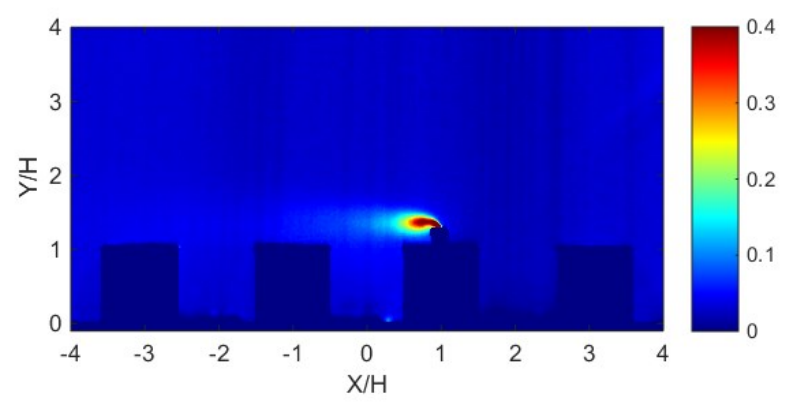

Fig. 9. Mean non- dimensional concentration $\mathrm{C} / \mathrm{C}_{0}$ field $\left(\mathrm{C}_{0}\right.$ is the mean concentration measured at the top of the chimneystack) for flat roof with a chimneystack (on the middle of the roof) with $\mathrm{h} / \mathrm{H}=0.25$; the flow moves from the right to the left. 


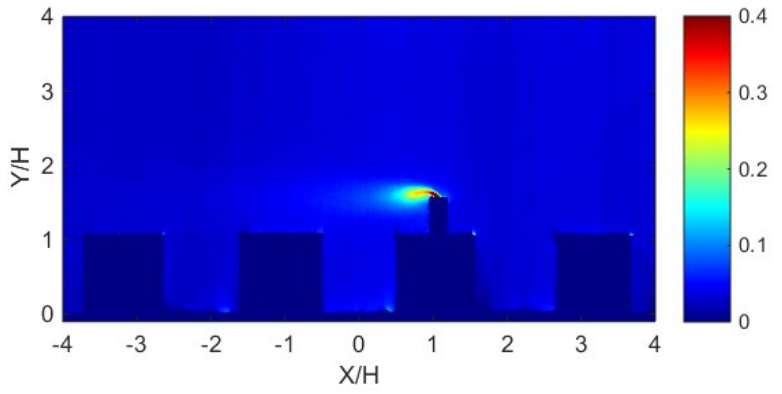

Fig. 10. Mean non- dimensional concentration $\mathrm{C} / \mathrm{C}_{0}$ field $\left(\mathrm{C}_{0}\right.$ is the mean concentration measured at the top of the chimneystack) for flat roof and a chimneystack (on the middle of the roof) with $\mathrm{h} / \mathrm{H}=0.50$; the flow moves from the right to the left.

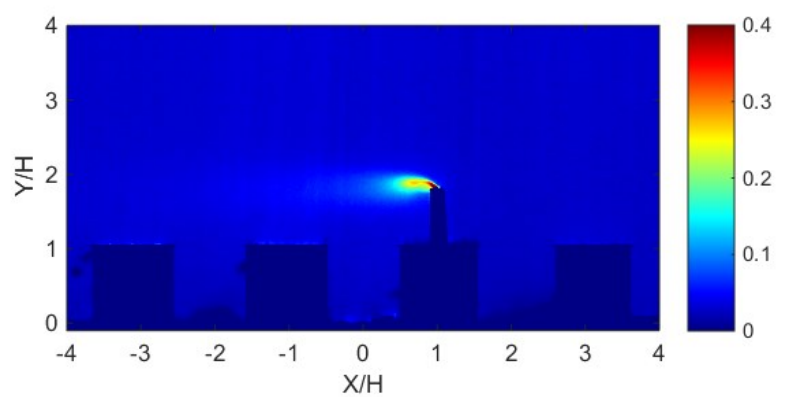

Fig. 11. Mean non-dimensional concentration $C / C_{0}$ field $\left(C_{0}\right.$ is the mean concentration measured at the top of the chimneystack) for flat roof and a chimneystack (on the middle of the roof) with $\mathrm{h} / \mathrm{H}=0.75$; the flow moves from the right to the left.

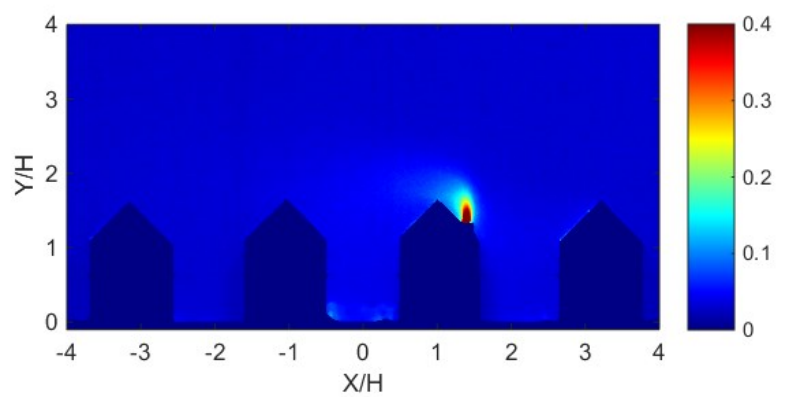

Fig. 12. Mean non- dimensional concentration $\mathrm{C} / \mathrm{C}_{0}$ field $\left(\mathrm{C}_{0}\right.$ is the mean concentration measured at the top of the chimneystack) for pitched roof and a chimneystack (on the upstream pitch) with $\mathrm{h} / \mathrm{H}=0.25$; the flow moves from the right to the left.

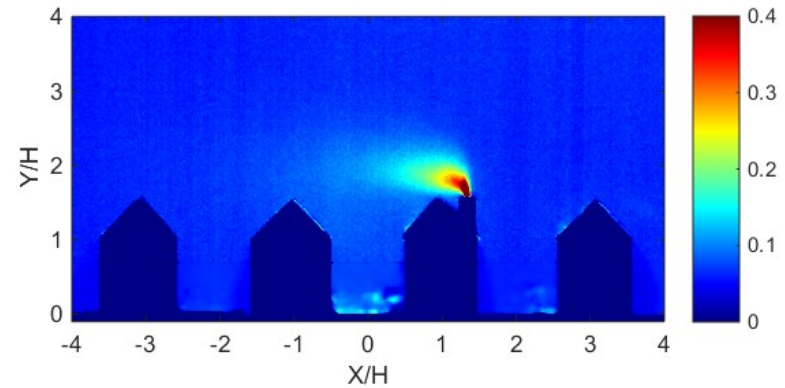

Fig. 13. Mean non- dimensional concentration $\mathrm{C} / \mathrm{C}_{0}$ field $\left(\mathrm{C}_{0}\right.$ is the mean concentration measured at the top of the chimneystack) for pitched roof and a chimneystack (on the upstream pitch) with $\mathrm{h} / \mathrm{H}=0.50$; the flow moves from the right to the left.

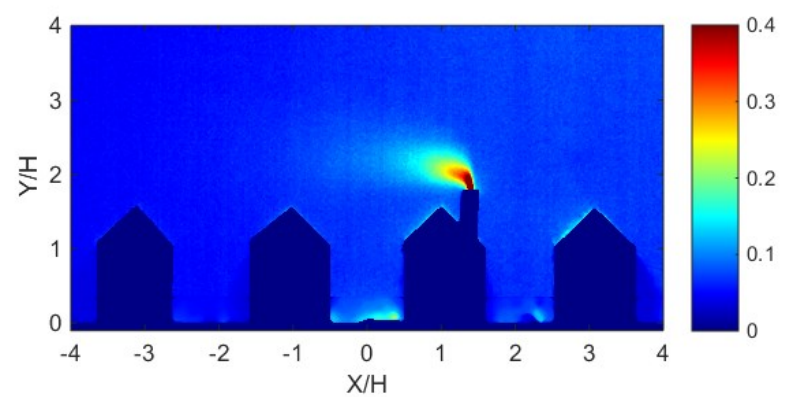

Fig. 14. Mean non- dimensional concentration $C / C_{0}$ field $\left(C_{0}\right.$ is the mean concentration measured at the top of the chimneystack) for pitched roof and a chimneystack (on the upstream pitch) with $\mathrm{h} / \mathrm{H}=0.75$; the flow moves from the right to the left.

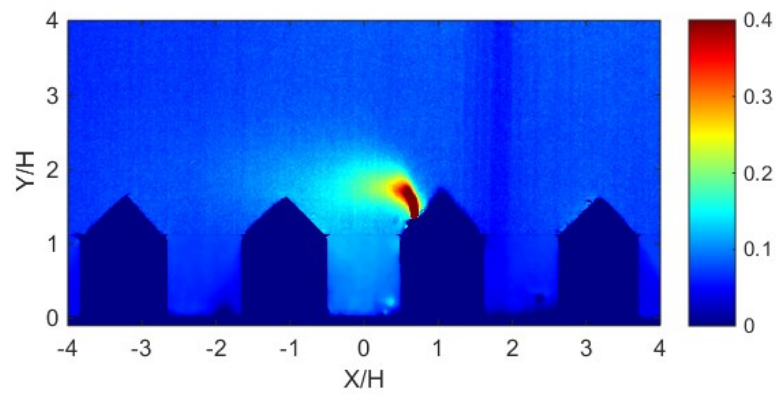

Fig. 15. Mean non- dimensional concentration $C / C_{0}$ field $\left(C_{0}\right.$ is the mean concentration measured at the top of the chimneystack) for pitched roof and a chimneystack (on the downstream pitch) with $\mathrm{h} / \mathrm{H}=0.25$; the flow moves from the right to the left. 


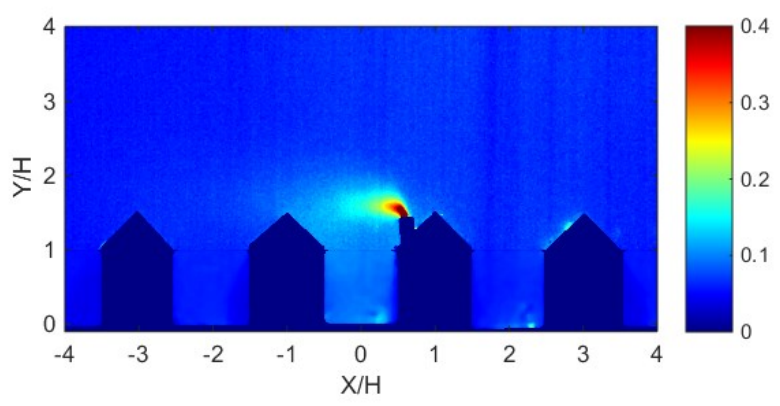

Fig. 16. Mean non- dimensional concentration $\mathrm{C} / \mathrm{C}_{0}$ field $\left(\mathrm{C}_{0}\right.$ is the mean concentration measured at the top of the chimneystack) for pitched roof and a chimneystack (on the downstream pitch) with $\mathrm{h} / \mathrm{H}=0.50$; the flow moves from the right to the left.

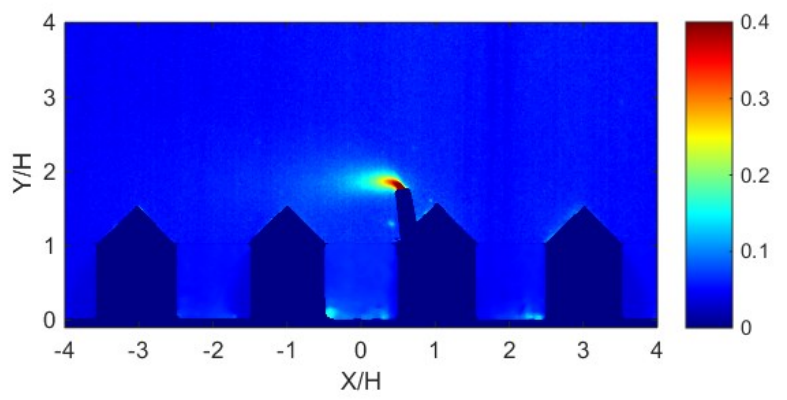

Fig. 17. Mean non-dimensionalised concentration $\mathrm{C} / \mathrm{C}_{0}$ field $\left(\mathrm{C}_{0}\right.$ is the mean concentration measured at the top of the chimneystack) for pitched roof and a chimneystack (on the downstream pitch) with $\mathrm{h} / \mathrm{H}=0.75$; the flow moves from the right to the left.

\subsubsection{Influence of the shape of the roof}

A first analysis on the concentration fields regards the influence of the shape of the roof on the development and dispersion of the plume.

The presence of the flat roof (Figures from 9 to 11) seems to favour the dilution of the contaminant plume, as the accumulation area inside the canyon looks smaller than in the other cases. As the chimneystack height $\mathrm{h} / \mathrm{H}$ increases, the accumulation zone further decreases, but the plume becomes wider, since its widening is less and less obstructed by the presence of the buildings downstream.

The presence of the double-pitched roof (Figures from 12 to 17), if on the one hand guarantees a better ventilation and therefore a larger turbulence intensity in the upper area of the canyon, on the other increases the size of the vein detachment zone and, therefore, of the dragging zone, i.e. of the portion of pollutant plume that comes inside the canyon. Consequently, for the same height of the chimneystack, the plume is wider than in the case with flat roof but this not leads to a better dilution inside the canyon, where the pollutant accumulation is larger (than in the flat roof case).

\subsubsection{Influence of the position of the chimneystack}

A second analysis of the concentration fields regards the influence of the position of the chimneystack on the roof on the development and dispersion of the plume.

Considering the upstream position on the pitched roof, when the chimneystack is lower than the pitched roof peak $(h / H=0.25$, Figure 12), both the plume and the accumulation area have reduced dimensions and the plume remains mainly trapped upstream of the roof peack. As the chimneystack height increases $(\mathrm{h} / \mathrm{H}=0.50$, chimneystack with the same height as the pitched roof peak, Figure 13), the plume immediately encounters the roof and the dragging zone generated there: consequently, the plume is dragged inside the canyon, where it tends to accumulate near the canyon bottom. For the maximum chimneystack height $(\mathrm{h} / \mathrm{H}=0.75$, chimneystack higher than the pitched roof peak, Figure 14), the pollutant is released higher than the buildings and than the dragging area, so the plume can develop upwards and disperse in the atmosphere, with less pollutant accumulation inside the canyon.

The scenario is the opposite if we consider the chimneystack on the downstream position on the pitched roof: for the smallest height $\mathrm{h} / \mathrm{H}=0.25$ (Figure 15) the plume is inside the dragging area, so there is a relevant pollutant accumulation inside the canyon and in the area between the two roofs, recording the worst case scenario for the pollutant dilution inside the canyon among the various configurations analysed. By increasing the height of the chimneystack, the pollutant dispersion improves considerably.

\subsubsection{Concentration inside the canyon}

A third analysis regards the consequences of what explained in the previous two subsections, i.e. the maximum measured concentration inside the canyon, where people usually stay and/or work.

Figure 18 shows the trend of the maximum mean non-dimensional concentration $\mathrm{C}_{\mathrm{MAX}} / \mathrm{C}_{0}$, measured inside the canyon, versus the chimneystack height $h / H$, for the three positions tested. The space inside the canyon is defined as the one for $\mathrm{X} / \mathrm{H}=-0.5 \div+0.5$ and $\mathrm{Y} / \mathrm{H}=0 \div 1$. The values for the flat roof with the chimneystack in the middle are drawn with red circles, connected by a dashed line, the ones for the pitched roof with the chimneystack on the upstream pitch are drawn with black asterisks, connected by a solid line, and the ones for the pitched roof with the chimneystack on the downstream pitch are drawn with blue squares, connected by a dotted line.

Looking at Figure 18, it is clear that, at least for $\mathrm{h} / \mathrm{H}>0.5$, an increase in the chimneystack height causes a reduction of the pollutant concentration inside the canyon.

The values for the downstream chimneystack on the pitched roof (in blue) are always the highest: this is because, as shown above, in this configuration the pollutant plume tends to be trapped inside the dragging 
area generated by the recirculation zone, in turns caused by the detachment of the fluid vein due to the presence of obstacles (i.e. the buildings) to the flow. As visible from the comparison of Figures 7 and 8, this recirculation zone is larger in the case of pitched roofs.

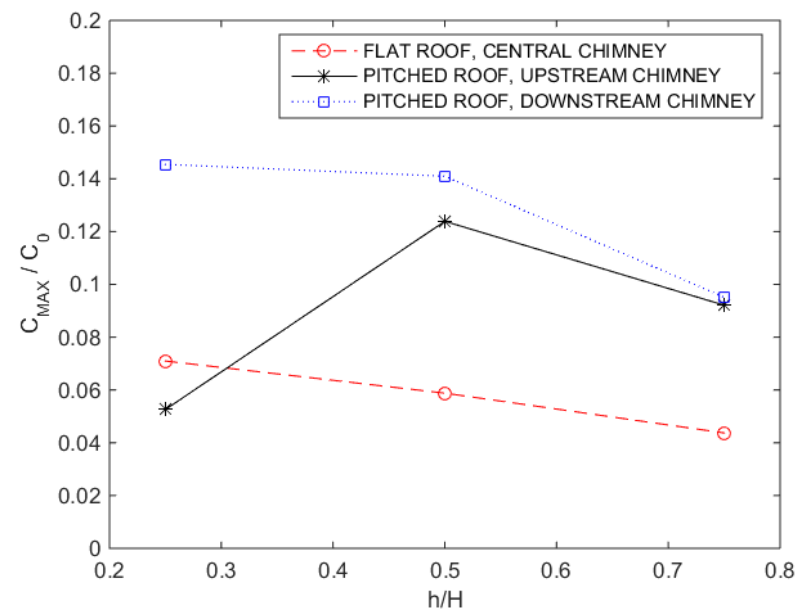

Fig. 18. Maximum mean non- dimensional concentration $\mathrm{C}_{\mathrm{MAX}} / \mathrm{C}_{0}\left(\mathrm{C}_{0}\right.$ is the mean concentration measured at the end of the chimneystack) inside the first canyon downstream the chimneystack, versus chimneystack height $\mathrm{h} / \mathrm{H}$, for the various chimneystack positions on the roof.

On the contrary, the lowest concentrations are found with the flat roof (in red), at least for the highest values of $\mathrm{h} / \mathrm{H}$, i.e. 0.50 and 0.75 : this because, as shown before, the plume can pass over the canyon without being strongly dragged inside the canyon, as the influence zone (and, consequently, the dragging area) is smaller with the flat roof than with the pitched roof.

The concentration values for the pitched roof with upstream chimneystack (in black) tend to be slightly lower than those of the pitched roof with downstream chimney and much higher than those of the flat roof. The only exception to this rule is for $\mathrm{h} / \mathrm{H}=0.25$, where the concentration in the case of pitched roof and upstream chimneystack has a lower value than the flat roof one. This is due to the fact that, as seen in Figure 12, the plume remains mainly trapped upstream of the roof peak, so it tends to not enter into the following canyon.

As a conclusion, we can state that for the highest chimneystacks, the flat roof is better than pitched one (because of the smaller influence zone), whilst for the lowest chimneystack the pitched roof with the chimneystack on the upstream pitch is the best configuration. Moreover, the worst configuration is when a pitched roof is coupled with a downstream chimneystack.

In addition, when pitched roofs are employed, an upstream chimneystack leads to a larger dilution than a downstream one.

\section{Conclusions}

In this experimental study, we have measured, via non-intrusive and quasi-continuous-in-space Digital image Analysis techniques, the velocity and concentration fields in flat and pitched roof idealised two-dimensional urban canyons, with a chimneystack of different height and position on the roof releasing a tracer.

The results show that the presence of an inclined pitched roof influences the ventilation and the dispersion capacity of the pollutants, mainly because it increases the influence area above the roofs and, consequently, the dragging area. As the chimneystack height decreases, the concentration inside the canyon increases in all cases, except for the lowest chimneystack on the upstream pitch of the pitched roof. Results also show that, for the highest chimneystacks, the flat roof is better than pitched one (because of the smaller influence zone), whilst for the lowest chimneystack the pitched roof with the chimneystack on the upstream pitch is the best configuration. Furthermore, the worst configuration is when a pitched roof is coupled with a downstream chimneystack and, when pitched roofs are employed, an upstream chimneystack leads to a larger dilution than a downstream one.

The analysis of the modification induced, on the wind flow field and on the pollutant concentration inside the urban canyons (with particular relevance to the ground level and near the walls of buildings), by different shapes of the roof and heights and positions of the chimneystack, is a subject of particular interest for the implications on air quality in urban and industrial built environments. The results of this study could provide useful tools for the urban planners, aimed at improving the comfort and the health of inhabitants and workers.

The Authors would like to acknowledge Mr. Antonio Mascia.

\section{References}

1. Y. Tamura, Advanced Environmental Wind Engineering (Springer Berlin Heidelberg, New York, NY, 2016).

2. X. Xie, Z. Huang, and J. Wang, Atmos. Environ. 39, 4519 (2005).

3. S. Rafailidis, Bound.-Layer Meteorol. 85, 255 (1997).

4. M. F. Yassin, Atmos. Environ. 45, 5220 (2011).

5. Y. Takano and P. Moonen, J. Wind Eng. Ind. Aerodyn. 123, 107 (2013).

6. S. Ferrari, M. G. Badas, M. Garau, A. Seoni, and G. Querzoli, HARMO 2016 - 17th Int. Conf. Harmon. Atmospheric Dispers. Model. Regul. Purp. Proc. 351 (2016).

7. M. G. Badas, S. Ferrari, M. Garau, and G. Querzoli, J. Wind Eng. Ind. Aerodyn. 162, 24 (2017).

8. S. Ferrari, M. G. Badas, M. Garau, A. Seoni, and G. Querzoli, Int. J. Environ. Pollut. 62, 22 (2017).

9. M. Garau, M. G. Badas, S. Ferrari, A. Seoni, and G. Querzoli, Bound.-Layer Meteorol. 167, 123 (2018). 
10. R. N. Meroney, M. Pavageau, S. Rafailidis, and M. Schatzmann, J. Wind Eng. Ind. Aerodyn. 62, 37 (1996).

11. K. J. Craig, D. J. D. Kock, and J. A. Snyman, Int. J. Numer. Methods Eng. 44, 551 (1999).

12. Z. Bagieński, Environ. Prot. Eng. 32, 37 (2006).

13. C. Mensink and G. Cosemans, Environ. Model. Softw. 23, 288 (2008).

14. Z. Baratian-Ghorghi and N. B. Kaye, Sci. Total Environ. 443, 112 (2013).

15. Z. Baratian-Ghorghi and N. B. Kaye, J. Vis. 16, 29 (2013).

16. J. A. Souto, C. Moral, A. Rodríguez, S. Saavedra, J. J. Casares, and A. Hernández-Garces, Int. J. Environ. Pollut. 55, 139 (2014).

17. G. Ghermandi, S. Teggi, S. Fabbi, A. Bigi, and M. M. Zaccanti, Int. J. Environ. Sci. Technol. 12, 693 (2015).

18. G. Ghermandi, S. Fabbi, M. Zaccanti, A. Bigi, and S. Teggi, Atmospheric Pollut. Res. 6, 382 (2015).

19. Š. Nosek, L. Kukačka, R. Kellnerová, K. Jurčáková, and Z. Jaňour, Bound.-Layer Meteorol. 159, 259 (2016).

20. Š. Nosek, L. Kukačka, K. Jurčáková, R. Kellnerová, and Z. Jaňour, Environ. Pollut. 227, 125 (2017).

21. A. Di Bernardino, P. Monti, G. Leuzzi, and G. Querzoli, Int. J. Environ. Pollut. 62, 291 (2017).

22. A. Di Bernardino, P. Monti, G. Leuzzi, and G. Querzoli, Urban Clim. 24, 80 (2018).

23. A. D. Bernardino, P. Monti, G. Leuzzi, F. Sammartino, and S. Ferrari, HARMO 2017 - 18th Int. Conf. Harmon. Atmospheric Dispers. Model. Regul. Purp. Proc. 460 (2017).

24. T. R. Oke, Energy Build. 11, 103 (1988).

25. M. G. Badas, M. Garau, G. Querzoli, L. Salvadori, and S. Ferrari, Int. J. Environ. Pollut. In press, (2018).

26. C. Farell and A. K. S. Iyengar, J. Wind Eng. Ind. Aerodyn. 79, 11 (1999).

27. B. Blocken, Build. Environ. 91, 219 (2015).

28. Hoydysh, W.G., Griffiths, R.A., and Owaga, Y., in Proc. 67th Annu. Meet. Air Pollut. Control Assn Denver Colo. June 9-13 1974 (1974).

29. S. Ferrari, EPJ Web Conf. 143, 01001 (2017).

30. L. A. Besalduch, M. G. Badas, S. Ferrari, and G. Querzoli, EPJ Web Conf. 45, 01012 (2013).

31. L. A. Besalduch, M. G. Badas, S. Ferrari, and G. Querzoli, EPJ Web Conf. 67, 02007 (2014).

32. S. Ferrari and G. Querzoli, J. Hydraul. Res. 48, 632 (2010).

33. S. Ferrari and G. Querzoli, EPJ Web Conf. 92, 02018 (2015).

34. S. Ferrari, M. Badas, and G. Querzoli, Water 10, 726 (2018).

35. S. Ferrari, M. G. Badas, and G. Querzoli, EPJ Web Conf. 180, 02025 (2018).

36. S. Ferrari, M. G. Badas, and G. Querzoli, EPJ Web Conf. 114, 02022 (2016).

37. G. Querzoli, Atmos. Environ. 30, 2821 (1996).

38. M. G. Badas and G. Querzoli, Exp. Fluids 50, 1093 (2011).
39. F. Simone, M. G. Badas, L. A. Besalduch, and Q. Giorgio, Int. Symp. Turbul. Shear Flow Phenom. TSFP 2013 (2013).

40. M. Garau, M. G. Badas, S. Ferrari, A. Seoni, and G. Querzoli, Int. J. Environ. Pollut. In press, (2018).

41. S. Ferrari, L. Rossi, and J. C. Vassilicos, in $A d v$. Turbul. XI - Proc. 11th EUROMECH Eur. Turbul. Conf. (2007), pp. 485-487.

42. S. Ferrari and L. Rossi, Exp. Fluids 44, 873 (2008).

43. S. Ferrari, P. Kewcharoenwong, L. Rossi, and J. C. Vassilicos, in IUTAM Symp. Flow Control MEMS, edited by J. F. Morrison, D. M. Birch, and P. Lavoie (Springer Netherlands, Dordrecht, 2008), pp. 267-272.

44. S. Lardeau, S. Ferrari, and L. Rossi, Phys. Fluids 20, 127101 (2008).

45. L. Rossi, S. Bocquet, S. Ferrari, J. M. Garcia de la Cruz, and S. Lardeau, Int. J. Heat Fluid Flow 30, 505 (2009).

46. M. Garau, M. G. Badas, S. Ferrari, A. Seoni, and G. Querzoli, HARMO 2017 - 18th Int. Conf. Harmon. Atmospheric Dispers. Model. Regul. Purp. Proc. 470 (2017).

47. M. G. Badas, S. Espa, S. Fortini, and G. Querzoli, EPJ Web Conf. 92, 02004 (2015).

48. S. Espa, M. G. Badas, S. Fortini, G. Querzoli, and A. Cenedese, Eur. J. Mech. - BFluids 35, 9 (2012). 